\title{
Vanadium Catalyzed Synthesis of Cyclic Organic Carbonates
}

\author{
Alessia Coletti, ${ }^{[c]}$ Christopher J. Whiteoak, ${ }^{[a]}$ Valeria Conte, ${ }^{*[c]}$ and Arjan W. Kleij*[a, b]
}

Vanadium complexes bearing easily synthesized, differently
functionalized salen and salphen ligands were prepared and
tested for their ability to catalyze the cycloaddition of carbon
dioxide to epoxides resulting in cyclic organic carbonates. The
reactivity of the prepared catalysts dramatically increases when
a coordinating hydroxyl group is present as a substituent in
the organic epoxide. The commercially available [VO(acac) $\left.{ }_{2}\right]$
complex was used as reference compound, and, in this case, we found that $\mathrm{V}_{10} \mathrm{O}_{26} \cdot\left(\mathrm{NBu}_{4}\right)_{4}$ was formed during the catalytic reactions. This compound, characterized by $\mathrm{X}$-ray diffraction analysis, is likely the active catalyst, and it results in significantly better yields of cyclic carbonates compared to those obtained with Schiff base containing vanadyl complexes. The high activity of the mixed polyoxo vanadyl-vanadate complex marks it as a powerful catalyst within the context of $\mathrm{CO}_{2}$ fixation chemistry.

\section{Introduction}

The synthesis of organic (poly)carbonates has attracted considerable attention because of the potential uses of this class of compound in various consumer-based products, such as batteries and aircraft windows. ${ }^{[1]}$ From a sustainability point of view, current processes for the synthesis of cyclic carbonates suffer from several disadvantages. They often involve harsh reaction conditions and unfavorable reagents, such as the highly toxic reagent phosgene. ${ }^{[2]} \mathrm{A}$ much greener alternative synthesis for cyclic carbonates involves the highly atom-economical reaction of $\mathrm{CO}_{2}$ with epoxides; for this reaction, transition metal catalysis has been extensively explored. ${ }^{[3]}$ Typically, a Lewis acid metal complex is combined with a nucleophilic co-catalyst, which fulfills a number of important requirements such as mutual tolerance, high compatibility, and stability under a wide range of conditions. Despite the extensive studies of (transition) metal catalyzed cyclic carbonate synthesis, the discovery of catalysts able to operate under mild (ambient) conditions remains a major academic challenge. ${ }^{[4]}$

From a sustainability point of view, the choice of catalyst is extremely important; it has to be catalytically active under mild conditions, relatively non-toxic, and, ideally, accessible from renewable sources. A large number of studies have been reported regarding the use of Schiff base ligands, such as salen [1,2-bis-(salicylideneamino)-ethane] or salphen [1,2-bis(salicylideneamino)-benzene] as ligands for metal complexes comprising $\mathrm{Cr}^{\prime \prime \prime}, \mathrm{Co}^{\prime \prime \prime}, \mathrm{Al}^{\prime \prime \prime}, \mathrm{Sn}^{\prime \prime \prime} / \mathrm{V}, \mathrm{Cu}^{\prime \prime}$, and $\mathrm{Zn}^{\prime \prime}$ metal ions in the context of organic carbonate synthesis. ${ }^{[5]}$ The use of Schiff base ligands presents a number of advantages among which are their ease of synthesis, the simple electronic and steric modulation, and the versatility in their complexation behaviors, which allow the generation of many metal complexes with a variety of properties. ${ }^{[6]}$ The choice of metal, apart from economical reasons, is also dictated by its potential toxicity, affecting the overall sustainability of the process. ${ }^{[7]}$
Vanadium is an abundant and relatively non-toxic metal. ${ }^{[8]}$ It is also known to act as a Lewis acid catalyst, especially in complexes with high-valent $\mathrm{V}^{\mathrm{V}}$ or $\mathrm{V}^{\mathrm{V}}$ metal centers. Reports of vanadium-mediated oxidation of organic substrates such as olefins, thioethers, amines, and phosphines, using a number of oxidizing agents, have been published..$^{[9]}$ Lee and co-workers reported that a simple and commercially available vanadium trichloride catalyst was able to catalyze the reaction between a variety of terminal epoxides/cyclohexene oxide and carbon dioxide. ${ }^{[10]}$ Unfortunately, though, this required elevated temperatures $\left(90-120^{\circ} \mathrm{C}\right)$ and pressures $(1.5 \mathrm{MPa}=14.8 \mathrm{bar})$. Therefore, the search for a $\mathrm{V}$ catalyzed procedure (Scheme 1) providing good activity under mild reaction conditions continues to attract huge interest. A general system for preparing a wide range of functional cyclic carbonates has not yet been reported.

After considering the issues mentioned above, we focused our attention on vanadium compounds, such as the easily pre-

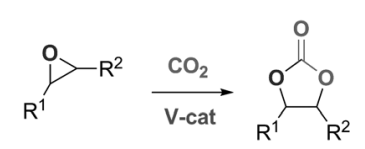

Scheme 1. Vanadium catalyzed synthesis of cyclic carbonates.

[a] Dr. C. J. Whiteoak, Prof. Dr. A. W. Kleij

Institute of Chemical Research of Catalonia (ICIQ)

Av. Països Catalans 16, 43007-Tarragona (Spain)

Fax: $(+34)$ 977-920-828

E-mail:akleij@iciq.es

[b] Prof. Dr. A. W. Kleij

Catalan Institute of Research and Advanced Studies (ICREA)

Pg. Lluís Companys 23, 08010-Barcelona (Spain)

[c] A. Coletti, Prof. Dr. V. Conte

Department of Chemical Sciences and Technologies

University of Rome Tor Vergata

Via Ricerca Scientifica snc, 00133 Rome (Italy)

E-mail:valeria.conte@uniroma2.it

Supporting information for this article is available on the WWW under http://dx.doi.org/10.1002/cctc.201100398. 
pared vanadyl salphen and salen complexes, for the synthesis of cyclic organic carbonates from epoxides and $\mathrm{CO}_{2}$ (Scheme 1). The catalytic results were compared with those gathered for the commercially available $\mathrm{V}^{\mathrm{IV}}$ complex [VO(acac) ${ }_{2}$ ] (acac = acetylacetonate). In the reactions carried out with these latter complexes, we observed the precipitation of a new species that is most likely responsible for the observed activity. The structure of this active component in the formation of five-membered carbonates was elucidated by various analytical techniques; formation a decavanadate complex was unambiguously demonstrated. The presence of mostly $\mathrm{V}^{\mathrm{V}}$ centers in this polyoxometalate (POM) seems to illustrate the importance of this high oxidation state for achieving catalytic reactivity.

\section{Results and Discussion}

A series of differently substituted $\mathrm{V}^{\mathrm{IV}}(\mathrm{O})$ salen and $\mathrm{V}^{\mathrm{IV}}(\mathrm{O})$ salphen complexes bearing electron-donating and electron-withdrawing groups on the aromatic rings of the ligand scaffold (compounds $\mathbf{2 a - 2} \mathbf{f}$ and $\mathbf{3 a - 3} \mathbf{f}$; Scheme 2) were prepared and

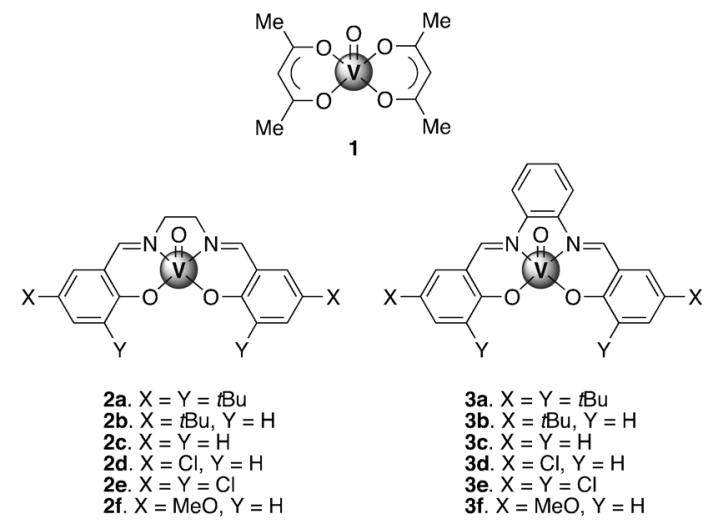

Scheme 2. Vanadium-based catalysts used for the investigation of the $\mathrm{CO}_{2}$ addition reaction with 1,2-epoxyhexane.

screened as potential catalysts for the cycloaddition reaction of $\mathrm{CO}_{2}$ and 1,2-epoxyhexane in the presence of $\mathrm{NBu}_{4} \mathrm{I}(\mathrm{Bu}=$ butyl) as co-catalyst, under mild conditions $\left(45^{\circ} \mathrm{C}, 1 \mathrm{MPa} \mathrm{CO}_{2}\right.$ pressure) and using mesitylene as an internal standard. The results obtained are shown in Table 1, as are those obtained with the reference compound $\left[\mathrm{VO}(\mathrm{acac})_{2}\right]$. The reaction conditions were chosen on the basis of the best results obtained in previous work using other metal complexes as catalysts. ${ }^{[11]}$ Methyl ethyl ketone (MEK) was used as the solvent, taking into account that it is one of the most efficient solvents for solubilization of $\mathrm{CO}_{2} \cdot{ }^{[12]}$

The electronic effect of the substituents on the vanadium centers in these VO(salen) and VO(salphens) compounds was investigated with cyclic voltammetry (Supporting Information). The redox potential $E_{\mathrm{p}}$ of the $\mathrm{V}^{\mathrm{IV}} / \mathrm{V}^{\mathrm{V}}$ couple increased both in the salen and salphen series of vanadyl complexes in agreement with the variation of the electron density on the metal caused by the presence of the different substituents. The more positive redox potentials of the salphen complexes with re-
Table 1. Vanadium catalyzed conversion of various mono-substituted epoxides and $\mathrm{CO}_{2}$ into the corresponding monocyclic carbonate under different reaction conditions. ${ }^{\text {[a] }}$

\begin{tabular}{|c|c|c|c|c|c|}
\hline Substrate & Catalyst & Entry & $\begin{array}{l}T \\
{\left[{ }^{\circ} \mathrm{C}\right]}\end{array}$ & $\begin{array}{l}p\left(\mathrm{CO}_{2}\right) \\
{[\mathrm{MPa}]}\end{array}$ & $\begin{array}{l}\text { Yield } \\
{[\%]}\end{array}$ \\
\hline \multirow{11}{*}{$n \mathrm{Bu}^{\prime}$} & 1 & $1^{[\mathrm{b}]}$ & 45 & 1 & 75 \\
\hline & & 2 & 45 & 1 & 100 \\
\hline & & 3 & 35 & 1 & 87 \\
\hline & & 4 & 25 & 1 & 57 \\
\hline & & 5 & 25 & 0.2 & 63 \\
\hline & & $6^{[c]}$ & 25 & 0.2 & 91 \\
\hline & & $7^{[\mathrm{d}]}$ & 35 & 1 & 72 \\
\hline & & $8^{[\mathrm{e}]}$ & 45 & 1 & 39 \\
\hline & $2 d$ & 9 & 45 & 1 & 3 \\
\hline & $3 c$ & 10 & 45 & 1 & 3 \\
\hline & $4 \mathrm{~b}$ & 11 & 45 & 1 & 6 \\
\hline \multirow{5}{*}{$\mathrm{HOCH}_{2}$} & 1 & 12 & 45 & 1 & 90 \\
\hline & & 13 & 35 & 1 & 75 \\
\hline & & 14 & 35 & 0.2 & 60 \\
\hline & & $15^{[\mathrm{cc}]}$ & 25 & 0.2 & 87 \\
\hline & $3 c$ & 16 & 45 & 1 & 55 \\
\hline \multirow[b]{2}{*}{$\mathrm{Ph}^{\prime}$} & 1 & 17 & 45 & 1 & 69 \\
\hline & & 18 & 25 & 0.2 & 48 \\
\hline \multirow[b]{2}{*}{$\mathrm{PhCH}_{2}^{\prime}$} & 1 & 19 & 45 & 1 & 100 \\
\hline & & 20 & 25 & 0.2 & 96 \\
\hline $\mathrm{MeOCH}_{2}$ & 1 & 21 & 45 & 1 & 72 \\
\hline $\mathrm{ClCH}_{2}^{\prime}$ & 1 & 22 & 45 & 1 & 96 \\
\hline & 1 & 23 & 45 & 1 & 58 \\
\hline
\end{tabular}

[a] Reaction conditions: substrate $(0.4 \mathrm{M})$; mesitylene $(0.4 \mathrm{M})$; catalyst $(0.01 \mathrm{M}, 2.5 \mathrm{~mol} \%)$; co-catalyst $\left(\mathrm{NBu}_{4} \mathrm{l}, 0.01 \mathrm{M}, 2.5 \mathrm{~mol} \%\right)$; solvent (2-butanone $=\mathrm{MEK}, 5.0 \mathrm{~mL}$ ); reaction time $=18 \mathrm{~h}, p\left(\mathrm{CO}_{2}\right)=1.0 \mathrm{MPa}$. [b] Catalyst loading is $1 \mathrm{~mol} \%$. [c] Co-catalyst concentration was $0.02 \mathrm{M}(5 \mathrm{~mol} \%)$. [d] $\mathrm{NBu}_{4} \mathrm{Br}$ was used as co-catalyst. [e] $\mathrm{MeCN}$ was used as solvent.

spect to the salen ones indicates that the aromatic ring confers to vanadium a higher Lewis acidity.

For comparison, data for the reactions with $\mathrm{V}^{\mathrm{IV}}(\mathrm{O})$ salen $\mathbf{2} \mathbf{d}$ and $V^{1 V}(O)$ salphen $\mathbf{3 c}$, and triflate $V^{V}$ salphen species $4 \mathrm{c}$ (Scheme 3) are given in Table 1 (entries 9, 10, 11, and 16, respectively), but the yields of cyclic carbonates proved to be generally low throughout the entire range of catalysts, despite the variation in the nature of the vanadium center. $^{[13]}$ However, when 1,2epoxy-3-hydroxypropane (glycidol) was used as the substrate, the reactivity of catalyst $3 \mathrm{c}$ increased significantly, giving rise to $55 \%$ yield for the corresponding cyclic

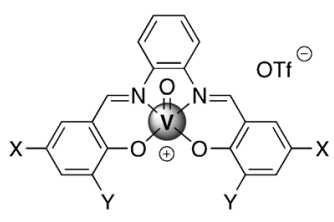

4a. $X=Y=t B u$ 4b. $X=Y=H$ 4c. $\mathrm{X}=\mathrm{Cl}, \mathrm{Y}=\mathrm{H}$

Scheme 3. $V^{V}$ salphen complexes used as catalyst for the cycloaddition of $\mathrm{CO}_{2}$ to 1,2-epoxyhexane. 
carbonate (Table 1, entry 16). This is likely due to the coordination of the hydroxyl group to the salphen scaffold which increases the binding affinity between the substrate and the catalyst. Further support for this hypothesis was derived from $\mathrm{X}$ ray diffraction studies carried out for $\mathbf{3} \mathbf{b}$ (Figure 1 ) in which the $V^{\mathrm{IV}}$ complex has a methanol molecule hydrogen-bonded to one of the phenolic $\mathrm{O}$ atoms of the salphen ligand.

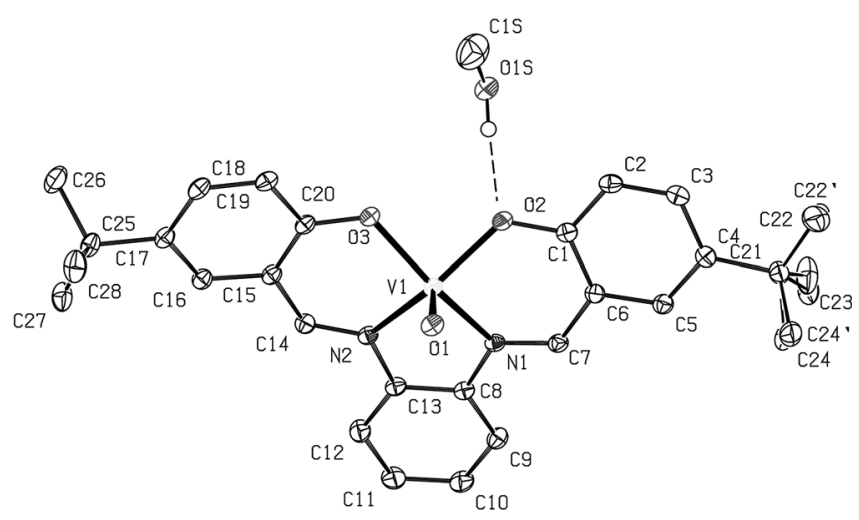

Figure 1. X-ray molecular structure for $\mathbf{3} \mathbf{b}$. Co-crystallized solvent molecules are omitted for clarity except for the hydrogen-bonded $\mathrm{MeOH}$ to $\mathbf{3} \mathbf{b}$. One of the tert-butyl $(t \mathrm{Bu})$ groups shows a rotational disorder, and the disorder in the $\mathrm{MeOH}$ is not shown here. Selected bond distances/angles $\left[\AA{ }^{\circ}\right]$ : $\mathrm{V}(1)-\mathrm{O}(1)=1.6011(9), \mathrm{V}(1)-\mathrm{O}(2)=1.9452(9), \mathrm{V}(1)-\mathrm{O}(3)=1.9250(8)$, $\mathrm{V}(1)-\mathrm{N}(1)=2.0611(10), \mathrm{V}(1)-\mathrm{N}(2)=2.0722(10) ; \mathrm{N}(1)-\mathrm{V}(1)-\mathrm{O}(1)=103.34(4)$, $\mathrm{N}(1)-\mathrm{V}(1)-\mathrm{O}(3)=148.68(4), \mathrm{N}(2)-\mathrm{V}(1)-\mathrm{O}(2)=143.75(4), \mathrm{O}(2)-\mathrm{V}(1)-\mathrm{O}(1)$ $=108.91(4), \mathrm{O}(3)-\mathrm{V}(1)-\mathrm{O}(1)=107.36(4)$.

In addition to the salen and salphen vanadyl complexes, the commercially available $\left[\mathrm{VO}(\mathrm{acac})_{2}\right]$ was also tested to serve as a reference compound. Interestingly, it turned out to be much more active than the VO(salen) complexes. Previously, Darensbourg and co-workers reported that $\left[\mathrm{VO}(\mathrm{acac})_{2}\right]$ is a Lewis acid catalyst for the synthesis of trimethylene carbonates (TMC, six-membered cyclic carbonates) from (substituted) trimethylene oxides (oxetanes) and $\mathrm{CO}_{2}$ under relatively mild conditions using tetrabutylammonium bromide as the co-catalyst. ${ }^{[14]}$ Therefore, the catalytic activity observed for [VO(acac $\left.)_{2}\right]$ is not fully unexpected, and the previous results concerning the formation of TMC was explained by a prior formation of an oxetane-adduct from the starting vanadium complex. However, in our work focusing on five-membered cyclic carbonates and a slightly different co-catalyst $\left(\mathrm{NBu}_{4} \mathrm{l}\right)$, we found evidence that the actual catalytic species likely involves a $\left[\mathrm{VO}(\mathrm{acac})_{2}\right]$ derivative (see below). In fact, a dark purple precipitate ${ }^{[15]}$ was always present at the end of the reaction carried out with this metal precursor. This solid was recovered by filtration, used in a subsequent catalytic run and proved to be catalytically active. It is not possible to fully compare the observed yields with respect to the starting vanadium species $\left[\mathrm{VO}(\mathrm{acac})_{2}\right]$ because of the much lower solubility of the purple solid in MEK after being isolated.

Because $\left[\mathrm{VO}(\mathrm{acac})_{2}\right.$ ] appears to be a good pre-catalyst for the formation of organic carbonates, the scope of the reaction was investigated further. As shown in Table 1, mono-substituted epoxides can be converted to the corresponding cyclic car- bonates by " $\mathrm{VO}(\mathrm{acac})_{2}$ " in good yields under mild reaction conditions. Using 1,2-epoxyhexane and 1,2-epoxy-3-hydroxypropane (Table 1, entries 1-16) as the substrates, the reaction was fully investigated by varying parameters, such as temperature, pressure and the amounts of catalyst and co-catalyst. The use of $\left[\mathrm{VO}(\mathrm{acac})_{2}\right]$ gave appreciable yields even when the reaction was performed at low pressure and ambient temperature ( $T=$ $25^{\circ} \mathrm{C}, p\left(\mathrm{CO}_{2}\right)=0.2 \mathrm{MPa}$, Table 1 , entries 5-6). The solvent MEK appears to play an important role in increasing the yields of the reaction because the use of $\mathrm{CH}_{3} \mathrm{CN}$ as the medium for the conversion of 1,2-epoxyhexane (forming a purple solution, but no observable precipitate) caused the yield to drop to $39 \%$ (Table 1, entry 8). A plausible explanation may be that solvents such as acetonitrile can potentially coordinate to the vanadium metal center in $\left[\mathrm{VO}(\mathrm{acac})_{2}\right]$ and/or the purple precipitate and, thus, compete with epoxide coordination. The precipitate is linked with an active form of the vanadium complex as discussed above.

The catalytic activity of "VO(acac) ${ }_{2}$ " was also tested for disubstituted epoxides which are considered more difficult to activate owing to an increased steric hindrance in the ring-opening of the oxirane ring by the halide nucleophile. Consequently, higher pressures and temperatures are needed to realize conversion of these substrates to the corresponding organic carbonates, and generally low yields were observed (Table 2).

\begin{tabular}{|c|c|c|c|c|}
\hline Entry & Substrate & $\begin{array}{l}T \\
{\left[{ }^{\circ} \mathrm{C}\right]}\end{array}$ & $\begin{array}{l}\text { Yield [\%] } \\
X=I\end{array}$ & $\begin{array}{l}\text { Yield [\%] } \\
\mathrm{X}=\mathrm{Br}\end{array}$ \\
\hline 1 & & 75 & $6^{[\mathrm{b}]}$ & $20^{[c]}$ \\
\hline 2 & & 75 & $10^{[\mathrm{d}]}$ & $33^{[\mathrm{e}]}$ \\
\hline 3 & $\mathrm{Me}$ & 75 & $5^{[f]}$ & $26^{[g]}$ \\
\hline & & 45 & 0 & - \\
\hline 4 & & 75 & 2 & 8 \\
\hline 5 & & $\begin{array}{l}45 \\
75\end{array}$ & $\begin{array}{r}4 \\
25\end{array}$ & $\begin{array}{l}14 \\
34\end{array}$ \\
\hline \multicolumn{5}{|c|}{$\begin{array}{l}\text { [a] Reaction conditions: substrate }(0.4 \mathrm{M}) \text {; mesitylene }(0.4 \mathrm{M}) \text {; catalyst } \\
(0.004 \mathrm{M}, 1 \mathrm{~mol} \%) \text {; co-catalyst }\left(\mathrm{NBu}_{4} \mathrm{X}, 0.05 \mathrm{M}, 2.5 \mathrm{~mol} \%\right) \text {, solvent (2-buta- } \\
\text { none }=\mathrm{MEK}, 5 \mathrm{~mL}) \text {; reaction time }=18 \mathrm{~h} ; p\left(\mathrm{CO}_{2}\right)=1 \mathrm{MPa} \text {. [b] }>99 \% \text { cis: } \\
\text { a mixture of } 85: 15 \text { trans/cis substrate was used. [c] 15:85 cis/trans. [d] } 4: 6 \\
\text { cis/trans. [e] } 91: 9 \text { cis/trans. [f] Only trans product was observed. [g] 12:88 } \\
\text { cis/trans. }\end{array}$} \\
\hline
\end{tabular}

In general, the substitution of iodide with bromide in the cocatalyst slightly increased the yields. The compound cis-2,3-dimethyl-oxirane is more easily activated than its trans isomer, and the reaction appears to have a reasonable degree of retention of configuration in most cases (Table 2, entries 2 and 3).

To gain insight into the formation of the purple complex in the $\left[\mathrm{VO}(\mathrm{acac})_{2}\right]$ catalyzed reactions, the reaction was carried 
out at $45^{\circ} \mathrm{C}$ in the absence of $\mathrm{CO}_{2}$ (in air), both with and without 1,2-epoxyhexane. It appears that the substrate is involved in the formation of the precipitate because only a small amount formed in the absence of the epoxide. Replacing the epoxide with water led to neither a color change nor precipitation, and the presence of a ten-fold increase in amount of the epoxide showed almost the same isolated yield for the precipitate $(46 \%$ after $18 \mathrm{~h})$. We then performed a series of experiments to investigate the effect of the solvent on the formation of this purple precipitate (see Supporting Information). Generally, the medium had a pronounced effect because the reactions carried out in THF, acetone, toluene, and MEK all produced the precipitate in moderate to excellent yields (31-99\%, $18 \mathrm{~h}$ ). The use of $\mathrm{CH}_{3} \mathrm{CN}, \mathrm{CHCl}_{3}$ or ethanol (EtOH) as solvents did not lead to any observable precipitation whereas the two former media showed a color change from initial green to purple. The purple precipitate formed during the catalytic cycle was analyzed by electrospray ionization mass spectrometry (ESI-MS), elemental analysis, infrared (IR), UV/Vis and ${ }^{51} \mathrm{~V}$ NMR spectroscopies, and X-ray diffraction.

The X-ray diffraction analysis of the crystallized purple precipitate provided useful information concerning the identity of this species (Figure 2). The structure comprises a tetraanionic

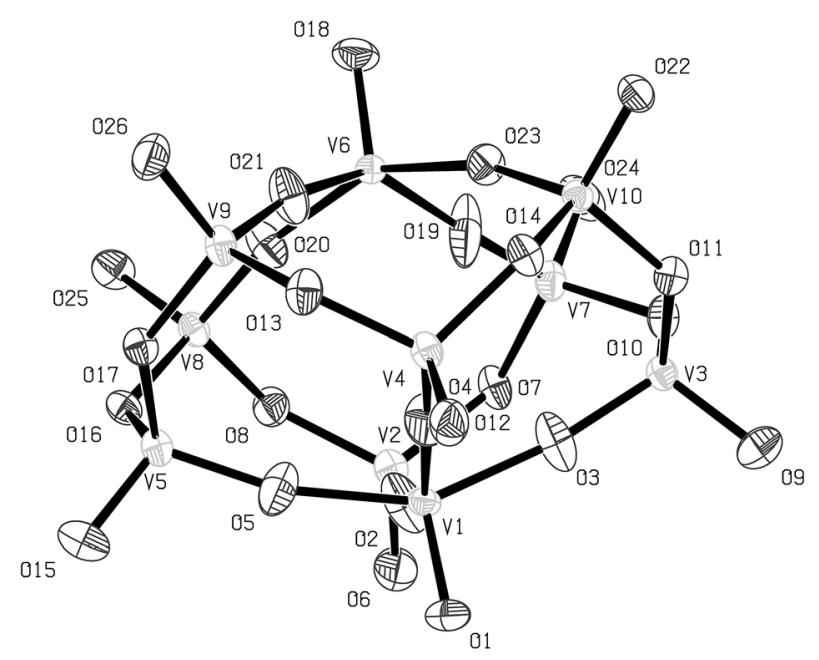

Figure 2. The tetraanionic portion of the X-ray molecular structure of the recrystallized purple precipitate. Hydrogen atoms, $\mathrm{NBu}_{4}$ cations (four), and cocrystallized solvent molecules are omitted for clarity. Selected bond distances $[\AA]$ : $\mathrm{V}(1)-\mathrm{O}(1)=1.565(3), \mathrm{V}(1)-\mathrm{O}(2)=1.927(4), \mathrm{V}(1)-\mathrm{O}(3)=1.943(4)$, $\mathrm{V}(1)-\mathrm{O}(4)=1.944(4), \mathrm{V}(1)-\mathrm{O}(5)=1.928(4) ; \mathrm{V}(3)-\mathrm{O}(9)=1.620(4)$,

$\mathrm{V}(3)-\mathrm{O}(10)=1.800(3), \mathrm{V}(3)-\mathrm{O}(11)=1.801(3), \mathrm{V}(3)-\mathrm{O}(3)=1.668(4)$. Both $\mathrm{V}(1)$ and $\mathrm{V}(6)$ centers are $\mathrm{V}^{\mathrm{IV}}$, and the others are $\mathrm{V}^{\mathrm{V}}$.

decavanadate with four $\mathrm{NBu}_{4}$ cations ${ }^{[16]}$ for which the molecular formula is $\mathrm{V}_{10} \mathrm{O}_{26}\left(\mathrm{NBu}_{4}\right)_{4}$. The starting acetylacetonate $\mathrm{V}$ complex seems to lose the two bidentate ligands to form a polyoxometalate complex. In this compound, there are eight $\mathrm{V}^{\mathrm{V}}$ and two $\mathrm{V}^{\mathrm{V}}$ centers, and because the highest oxidation state prevails, it seems that the catalytic activity originates from these metal centers. Note that the absence of iodide (the nucleophile used for the ring opening step in the catalytic studies reported in Tables 1 and 2) in the polyanionic structure should reduce the reactivity upon reusing the precipitate in cyclic carbonate formation; indeed a lower yield was observed when using the purple precipitate as the catalyst without additional co-catalyst. The presence of two paramagnetic $\mathrm{V}^{\mathrm{IV}}$ metals in the structure also explains why the complex does not show any peaks in the ${ }^{51} \mathrm{~V}$ NMR spectra in $\mathrm{CD}_{3} \mathrm{CN}$ or in $\mathrm{CD}_{2} \mathrm{Cl}_{2}$.

The ESI-MS of the purple precipitate presents two main peaks in the positive mode; the first peak at $m / z=242$ confirms the presence of $\mathrm{NBu}_{4}{ }^{+}$cations in the precipitate, and the second at $m / z=629.5$ is ascribed to a fragmentation of the decavanadate anion to form a $\mathrm{V}_{7} \mathrm{O}_{17}$ species (see Supporting Information). In the negative mode, one peak at $m / z=744.7$ is present, and it was assigned to the fragment anion $\mathrm{HV}_{8} \mathrm{O}_{21}$. Although the purple complex is air stable at room temperature, it presents moderate stability in solution because the color changes from dark violet to yellow in organic solvents, such as $\mathrm{CH}_{2} \mathrm{Cl}_{2}$ or $\mathrm{CH}_{3} \mathrm{CN}$, over prolonged periods. This may be ascribed to the formation of the "all $\mathrm{V}^{\mathrm{V}}$ " decavanadate with the formula $\mathrm{V}_{10} \mathrm{O}_{28}$ that is known to have a yellow color. Alternatively, the formation of a metavanadate species can be envisaged, which has been reported to be catalytically active in various reactions. ${ }^{[17]}$

The IR and UV/Vis spectroscopic data of the purple precipitate was compared with data from the literature ${ }^{[16]}$ and further supported the formation of the decavanadate (Supporting Information). The elemental analyses (carried out multiple times with samples from different reactions) always showed data consistent with the proposed molecular formula of the decavanadate. The formation of the vanadate was accelerated by the epoxide in the presence of the co-catalyst $\left(\mathrm{NBu}_{4} \mathrm{l}\right)$. The formation mechanism (Scheme 4) of this large decavanadate species

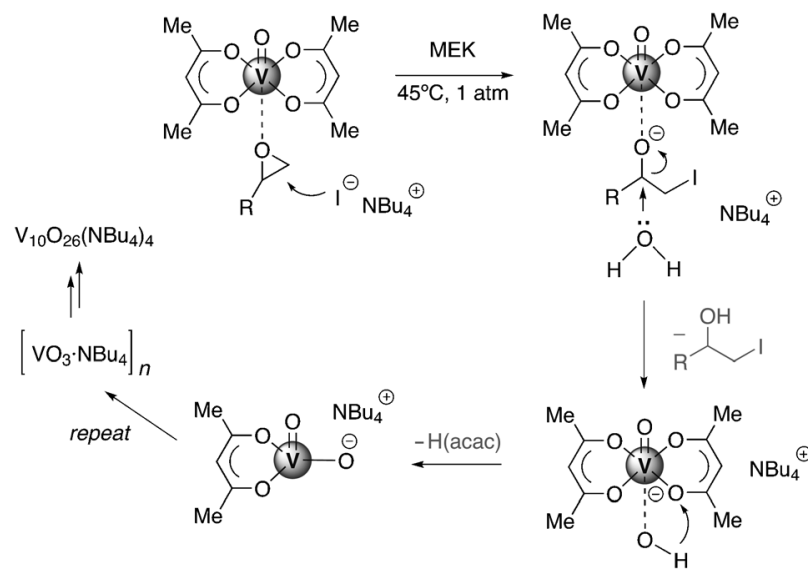

Scheme 4. Possible formation mechanism of the decavanadate species.

probably starts with the formation of the simple tetrahedral meta-vanadate from $\left[\mathrm{VO}(\mathrm{acac})_{2}\right]$ by acidic displacement of the two bidentate acetylacetonate ligands. The accelerating role of the epoxide may be explained by its potential to form an intermediate species with a V-alkoxide bond after iodide induced ring-opening. The fact that using oxetane as the substrate led 
to much smaller amounts of vanadate ${ }^{[15]}$ supports this view because the ring-opening of oxetanes is more difficult with halide nucleophiles. The basic alkoxide then could react with residual water to yield a $\mathrm{V}-\mathrm{OH}$ species from which $\mathrm{H}$-acac could be eliminated, forming a $\mathrm{V}-\mathrm{O}$ bond that is charge neutralized by $\mathrm{NBu}_{4}$. Subsequent elimination of the second acac ligand via a similar pathway could then lead to a $\mathrm{V}\left(\mathrm{O}_{3}\right)$ (metavanadate, yellow) and other higher-order vanadates that precede the eventual deca-vanadate formation.

\section{Conclusions}

In summary, a series of substituted salen and salphen vanadyl complexes were prepared and used as catalysts in the formation of cyclic organic carbonates from epoxides and $\mathrm{CO}_{2}$. The reactivities of the complexes were compared with commercially available $\left[\mathrm{VO}(\mathrm{acac})_{2}\right]$. The results indeed showed that vanadium may be an attractive and active metal in the presence of a suitable nucleophile as co-catalyst in the context of $\mathrm{CO}_{2}$ fixation chemistry. The presence of an alcohol group in the substrate (such as glycidol) allowed a possible ditopic binding to the metallosalen scaffold, thereby increasing the reactivity. Among all of the catalysts investigated, "VO(acac) ${ }_{2}$ " was by far the most active, and it can be used under very mild conditions $\left(25^{\circ} \mathrm{C}, p\left(\mathrm{CO}_{2}\right)=0.2-1.0 \mathrm{MPa}\right)$. Note that the higher activity of [ $\left.\mathrm{VO}(\mathrm{acac})_{2}\right]$ can be ascribed to the formation of a new decavanadate $\left(\mathrm{Bu}_{4} \mathrm{~N}\right)_{4} \mathrm{~V}_{10} \mathrm{O}_{26}$ complex that was isolated and fully characterized. This polyoxometalate, mainly comprising vanadium centers in a high oxidation state $(+5)$, may thus hold great promise for the development of new catalytic procedures that take advantage of the Lewis acidic nature of the $V^{V}$ metal centers within the structure.

\section{Experimental Section}

\section{Synthesis of the ligand precursors}

The salen and salphen ligands were prepared from commercially available starting materials following literature procedures. ${ }^{[18]}$ Two equivalents of the appropriate salicylaldehyde were dissolved in a minimal amount of boiling methanol $(\mathrm{MeOH})$. One equivalent of ethylenediamine or o-phenylendiamine was added and the solutions were left to cool to ambient temperature under stirring. The orange or yellow precipitates were recovered by filtration, washed with cold methanol and further purified by crystallization from ethanol when required. The purity of the ligand precursors was established by ${ }^{1} \mathrm{H}$ NMR spectroscopy.

\section{Synthesis of the vanadyl complexes}

Complexes $\mathbf{2 a}, \mathbf{2}$ c-2 f, $\mathbf{3}$ a, $\mathbf{3}$ c-3 f , and $\mathbf{4 a - 4 d}$ (Schemes 2 and 3) were prepared following the methods reported in the literature with slight modifications. ${ }^{[18]}$ The respective ligand was dissolved in a minimal amount of boiling methanol. A methanol solution of 1 equivalent of $\left[\mathrm{VO}(\mathrm{acac})_{2}\right]$ or $\left[\mathrm{V}(\mathrm{acac})_{3}\right]$ was added. The mixture was then allowed to cool to room temperature and kept at this temperature while stirring for $18 \mathrm{~h}$. The green or brown precipitate that formed was recovered by filtration and washed with methanol, triturated with diethyl ether, and dried. The known com- pounds obtained were characterized by either matrix-assisted laser desorption/ionization (MALDI) or ESI-MS. To the best of our knowledge, catalysts $\mathbf{2} \mathbf{b}$ and $\mathbf{3} \mathbf{b}$ have not been previously published, and a detailed experimental part for these derivatives is found below. Synthesis of $\mathrm{V}^{\mathrm{V}}$ complexes were obtained by dissolving the corresponding $\mathrm{V}^{\mathrm{IV}}$ complex in a minimal volume of $\mathrm{CH}_{2} \mathrm{Cl}_{2}$ under stirring at $0^{\circ} \mathrm{C}$, and bubbling $\mathrm{O}_{2}$ through the solution for $5 \mathrm{~min}$. After the addition of 1.2 equivalents of trifluoromethanesulfonic acid, a dark precipitate formed, and the reaction mixture was allowed to stir overnight. The solid $\mathrm{V}^{\mathrm{V}}$ complex was recovered by centrifugation $(6000 \mathrm{rpm})$ of the reaction mixture and decantation of the supernatant solution.

[VO(5-tBu-salen)] $2 b$ : The ligand 5-tBu-salen ( $250 \mathrm{mg}, 0.66 \mathrm{mmol})$ was dissolved in $60 \mathrm{~mL}$ of boiling methanol and a solution of 1 equiv of $\left[\mathrm{VO}(\mathrm{acac})_{2}\right]$ dissolved in $5 \mathrm{~mL}$ of methanol was added. After cooling to room temperature, the mixture was stirred for an additional $18 \mathrm{~h}$. The precipitate was recovered by filtration, washed with methanol, and dried. Yield: $195 \mathrm{mg}(0.44 \mathrm{mmol}), 66 \%$. UV/Vis (acetonitrile): $\lambda\left(\varepsilon_{\max }\right)=246 \mathrm{~nm}(56000), 278 \mathrm{~nm}(27000), 370 \mathrm{~nm}$ (9200); IR (neat): $\tilde{v}=466,476,529,558,717,806,833,983,1182$, $1257,1303,1332,1383,1470,1535,1620,2865,2955 \mathrm{~cm}^{-1}$; ESI(+)MS (MeOH): $m / z=468.2(M+N a)^{+}$(calcd 468.2); elemental analysis calcd (\%) for $\mathrm{C}_{24} \mathrm{H}_{30} \mathrm{~N}_{2} \mathrm{O}_{3} \mathrm{~V} \cdot 1 / 3{ }_{3} \mathrm{H}_{2} \mathrm{O}$ (451.45): C 63.85, H 6.85, N 6.21; found: C 63.85, H 6.63, N 6.26.

[VO(5-tBu-salphen)] $3 \boldsymbol{b}$ : The ligand 5-tBu-salphen (200 mg, $0.47 \mathrm{mmol}$ ) was dissolved in $100 \mathrm{~mL}$ of boiling methanol, and then a solution of 1 equiv of $\left[\mathrm{VO}(\mathrm{acac})_{2}\right.$ ] dissolved in $5 \mathrm{~mL}$ of methanol was added. The solution was cooled to room temperature and allowed to stir for eight hours. A large part of the solvent was evaporated under reduced pressure at $35^{\circ} \mathrm{C}$, and the solution was kept in the freezer overnight. The green precipitate was recovered by filtration, washed with methanol and diethyl ether $(20 \mathrm{~mL})$, and dried. Yield: $191 \mathrm{mg}(0.39 \mathrm{mmol}), 82 \%$. Crystals suitable for X-ray diffraction were obtained from methanol and the structure is shown in Figure 1. UV/Vis (acetonitrile): $\lambda\left(\varepsilon_{\max }\right)=246 \mathrm{~nm}(40900)$, $318 \mathrm{~nm}$ (22700), $409 \mathrm{~nm}$ (15400); IR (neat): $\tilde{v}=402,485,508,538$, $565,611,673,700,731,817,834,979,1146,1181,1258,1312,1362$, $1378,1462,1528,1576,1597,1615,2959 \mathrm{~cm}^{-1}$; ESI(+)-MS (MeOH): $\mathrm{m} / \mathrm{z}=516.2(\mathrm{M}+\mathrm{Na})^{+}$(calcd 516.2); elemental analysis calcd (\%) for $\mathrm{C}_{28} \mathrm{H}_{30} \mathrm{~N}_{2} \mathrm{O}_{3} \mathrm{~V} \cdot \mathrm{MeOH}$ (525.53): C 66.28, H 6.52, N 5.33; found: C $65.91, \mathrm{H} 6.69, \mathrm{~N} 5.40$.

\section{General procedure for the catalytic reactions}

All of the solutions were prepared in vials. The reagents were added in the order: catalyst, substrate, nucleophilic salt, mesitylene (the internal standard) and solvent (methyl ethyl ketone (MEK), $5 \mathrm{~mL}$ ). The solutions were stirred, subjected to ultrasonication to maximize the dissolution of the catalyst and then transferred to a stainless steel reactor. Catalytic reactions with chloro-substituted salphen and salen vanadium complexes were carried out in the presence of the solid catalyst because those catalysts are only partially soluble in MEK. The $\mathrm{CO}_{2}$ atmosphere was created by carrying out five cycles of pressurization at $0.5 \mathrm{MPa}$ and depressurization, and then stabilizing the pressure at $0.2 \mathrm{MPa}$. When a lower pressure was used, the reaction was degassed until reaching the value desired. The solutions were stirred for $18 \mathrm{~h}$ and heated when required. Analysis of the solutions were done by means of ${ }^{1} \mathrm{H}$ NMR in $\left[D_{6}\right]$ DMSO using mesitylene as an internal standard. The blank reaction was done without any metal complex in solution and showed no observable conversion at $T=45^{\circ} \mathrm{C}$ and $p\left(\mathrm{CO}_{2}\right)=1.0 \mathrm{MPa}$. 
Decavanadate $\left(\mathrm{Bu}_{4} \mathrm{~N}\right)_{4} \mathrm{~V}_{10} \mathrm{O}_{26}$ : A solution of [VO(acac) $\left.)_{2}\right](32.3 \mathrm{mg}$ $0.121 \mathrm{mmol}), \mathrm{NBu}_{4} \mathrm{l}(46.6 \mathrm{mg}, 0.126 \mathrm{mmol})$ and 1,2-epoxyhexane ( $30 \mu \mathrm{L}, 0.249 \mathrm{mmol}$ ) was stirred for $18 \mathrm{~h}$ at $45^{\circ} \mathrm{C}$. The solid $(9.8 \mathrm{mg}$ ) was isolated by filtration, washed with MEK, and dried. A second fraction of the product $(4.9 \mathrm{mg})$ was also isolated. Yield: $14.7 \mathrm{mg}$, purple solid $(0.00776 \mathrm{mmol}), 64 \%$, analyzed as the decavanadate. UV/Vis (acetonitrile): $\lambda\left(\varepsilon_{\max }\right)=324 \mathrm{~nm}$ (14500), $508 \mathrm{~nm}$ (1800). IR (neat): $\tilde{v}=399,656,837,881,954,994,1379,1482,2872$, $2954 \mathrm{~cm}^{-1}$. ESI(+)-MS (MeOH): $\mathrm{m} / z=629.5\left(\mathrm{HV}_{7} \mathrm{O}_{17}\right)^{+}$(calcd 629.5) $242.3\left(\mathrm{NBu}_{4}\right)^{+}$(calcd 242.3). ESI(-)-MS (MeOH): $\mathrm{m} / \mathrm{z}=744.7$ $\left(\mathrm{HV}_{8} \mathrm{O}_{21}\right)^{+}$(calcd 744.6). Elemental analysis calcd for $\mathrm{V}_{10} \mathrm{O}_{26} \cdot\left(\mathrm{NBu}_{4}\right)_{4} \cdot 2 \mathrm{H}_{2} \mathrm{O}$ (1931.28): C: $39.80, \mathrm{H}$ 7.72, N 2.90; found: C $39.62, \mathrm{H} 7.58, \mathrm{~N} 2.92$.

\section{Electrochemical measurements}

The cyclic voltammetry was carried out in DMF using tetrabutylammonium perchlorate (TBAP, re-crystallized from ethanol) as the electrolyte salt $(0.1 \mathrm{M})$. The vanadyl complexes were dissolved in the electrolyte solution. $\mathrm{A} \mathrm{Ag} / \mathrm{AgCl}$ electrode was used as the reference.

\section{X-ray diffraction studies}

The crystals were stable under atmospheric conditions; nevertheless they were prepared under inert conditions, and immersed in perfluoropolyether as the protecting oil for manipulation. Measurements were made on a Bruker-Nonius diffractometer equipped with an APPEX $24 \mathrm{~K} \mathrm{CCD}$ area detector, a FR591 rotating anode with $\mathrm{Mo}_{\mathrm{K} \alpha}$ radiation, Montel mirrors and a Kryoflex low temperature device $\left(T=173^{\circ} \mathrm{C}\right)$. Full sphere data collection was used with $\omega$ and $\phi$ scans. The programs used were: data collection Apex2 V2011.3 (Bruker-Nonius 2008), data reduction Saint+Version 7.60A (Bruker AXS 2008) and absorption correction SADABS V. 2008-1 (2008). The SHELXTL Version 6.10 (Sheldrick, 2000) ${ }^{[19]}$ program was used for the structure solution. The structure was refined using SHELXTL-97-UNIX VERSION.

Crystal data for $3 \boldsymbol{b}$ : Formula: $\mathrm{C}_{29} \mathrm{H}_{34} \mathrm{~N}_{2} \mathrm{O}_{4} \mathrm{~V} ; M_{\mathrm{r}}=525.52$; crystal size $0.15 \times 0.15 \times 0.03 \mathrm{~mm}$; monoclinic; space group $P 2_{1} / c ; a=$ 12.0214(8), $b=10.5465(7), c=21.2871(14) \AA ; \alpha=90, \beta=101.772(2)$, $\gamma=90^{\circ} ; \quad V=2642.1(3) \AA^{3} ; Z=4 ; \rho_{\text {calcd }}=1.321 \mathrm{mg} \mathrm{M}^{-3} ; \mu\left(\mathrm{Mo}_{\mathrm{K \alpha}}\right)=$ $0.412 \mathrm{~mm}^{-1} ; T=100(2) \mathrm{K} ; \theta(\min / \max )=1.73 / 30.04^{\circ} ; 7359$ reflections collected; 6476 unique reflections $\left(R_{\text {int }}=0.0298\right)$; refinement method: full-matrix least-squares on $F^{2}$; data/restraints/parameters: $7359 / 22 / 383 ;$ GoF on $F^{2}=1.046 ; R_{1}=0.0320$ and $w R_{2}=0.0865$ [I>2 $\sigma(l)] ; R_{1}=0.0384$ and $w R_{2}=0.0915$ (all data); largest diff. peak and hole: 0.791 and -0.380 e $\AA^{3}$ (CCDC 852356 contains the supplementary crystallographic data for this paper. These data can be obtained free of charge from The Cambridge Crystallographic Data Center via www.ccdc.cam.ac.uk/data_request/cif.)

Crystal data for decavanadate $\left(\mathrm{Bu}_{4} \mathrm{~N}\right)_{4} \mathrm{~V}_{10} \mathrm{O}_{26}$ : Formula: $\mathrm{C}_{70} \mathrm{H}_{156} \mathrm{~N}_{4} \mathrm{O}_{28} \mathrm{~V}_{10} ; M_{\mathrm{r}}=1982.35$; crystal size $0.20 \times 0.10 \times 0.03 \mathrm{~mm}$; orthorhombic; space group $P 2_{1} 2_{1} 2_{1} ; a=16.8869(18), b=17.0015(19)$, $c=33.697(3) \AA ; \quad \alpha=\beta=\gamma=90^{\circ} ; \quad V=9674.6(18) \AA^{3} ; \quad Z=4 ; \quad \rho_{\text {calcd }}=$ $1.361 \mathrm{mg} \mathrm{M}^{-3} ; \mu\left(\mathrm{Mo}_{\mathrm{Ka}}\right)=0.986 \mathrm{~mm}^{-1} ; \quad T=100(2) \mathrm{K} ; \theta(\min / \mathrm{max})=$ $1.34 / 25.44^{\circ} ; 17696$ reflections collected; 13822 unique reflections $\left(R_{\text {int }}=0.0625\right)$; refinement method: full-matrix least-squares on $F^{2}$; data/restraints/parameters: $17696 / 269 / 1105 ;$ GoF on $F^{2}=1.088$; $R_{1}=0.0593$ and $w R_{2}=0.1390[I>2 \sigma(I)] ; R_{1}=0.0851$ and $w R_{2}=$ 0.1546 (all data); largest diff. peak and hole: 1.002 and $-0.804 \mathrm{e}^{3}$ (CCDC 852355 contains the supplementary crystallographic data for this paper. These data can be obtained free of charge from The Cambridge Crystallographic Data Center via www.ccdc.cam.ac.uk/data_request/cif.)

\section{Acknowledgements}

Dr. P. Galloni is kindly acknowledged for helpful discussions. The COST-D40 Action is gratefully acknowledged for an STSM to AC. AWK and CW thank ICIQ and ICREA, the Consolider Ingenio 2010 (project Intecat, CSD 2006-0003), and the Spanish Ministry of Science and Innovation MICINN (CTQ 2008-02050 and CTQ201127385) for financial support.

Keywords: carbon dioxide fixation - homogeneous catalysis organic carbonates $\cdot$ salens $\cdot$ vanadates

[1] a) Carbon Dioxide as Chemical Feedstock (Ed.: M. Aresta), Wiley-VCH Weinheim, 2010; b) T. Sakakura, K. Kohno, Chem. Commun. 2009, 13121330 ; c) T. Sakakura, J. C. Choi, H. Yasuda, Chem. Rev. 2007, 107, 23652387; d) M. R. Kember, A. Buchard, C. K. Williams, Chem. Commun. 2011, 47, $141-163$; e) M. North, R. Pasquale, C. Young, Green Chem. 2010, 12, 1514-1539; f) D. J. Darensbourg, Chem. Rev. 2007, 107, 2388; g) C. Bruckmeier, B. Rieger, W. A. Herrmann, F. E. Kühn, Angew. Chem. 2011, 123, 8662-8690; Angew. Chem. Int. Ed. 2011, 50, 8510-8537.

[2] a) D. D. Berolzheimer, J. Ind. Eng. Chem. 1919, 11, 263; b) A. A. G. Shaikh, S. Sivaram, Chem. Rev. 1996, 96, 951.

[3] See for some illustrative examples: a) R. L. Paddock, S. T. Nguyen, Chem. Commun. 2004, 1622; b) D. J. Darensbourg, R. M. Mackiewicz, J. Am. Chem. Soc. 2005, 127, 14026; c) M. North, C. Young, Catal. Sci. Technol. 2011, 1, 93-99; d) A. Buchard, M. R. Kember, K. G. Sandeman, C. K. Williams, Chem. Commun. 2011, 47, 212; e) J. E. Dengler, M. W. Lehenmeier, S. Klaus, C. E. Anderson, E. Herdtweck, B. Rieger, Eur. J. Inorg. Chem. 2011, 336; f) I. Shibata, I. Mitani, A. Imakuni, A. Baba, Tetrahedron Lett. 2011, 52, 721 .

[4] For some examples that have been recently reported: a) M. R. Kember P. D. Knight, P. T. R. Reung, C. K. Williams, Angew. Chem. 2009, 121, 949 951; Angew. Chem. Int. Ed. 2009, 48, 931-933; b) A. Decortes, A. W. Kleij, ChemCatChem 2011, 3, $831-834$; c) W. Clegg, R. W. Harrington, M. North, R. Pasquale, Chem. Eur. J. 2010, 16, 6828-6843.

[5] A Decortes, A. M. Castilla, A. W. Kleij, Angew. Chem. 2010, 122, 10016 10032; Angew. Chem. Int. Ed. 2010, 49, 9822-9837.

[6] S. J. Wezenberg, A.W. Kleij, Angew. Chem. 2008, 120, 2388-2399; Angew. Chem. Int. Ed. 2008, 47, 2354-2364.

[7] R. Martin, A. W. Kleij, ChemSusChem 2011, 4, 1259-1263.

[8] A. Tracey, Vanadium compounds, ACS Symposium Series; American Chemical Society, Washington, DC, 1998.

[9] a) G. Licini, V. Conte, A. Coletti, M. Mba, C. Zonta, Coord. Chem. Rev. 2011, 255, 2345-2357; b) V. Conte, B. Floris, Dalton Trans. 2011, 40, 1419-1436; c) D. C. Crans, J. J. Smee, E. Gaidamauskas, L. Yang, Chem. Rev. 2004, 104, 849-902.

[10] T. Bok, E. K. Noh, B. Y. Lee, Bull. Korean Chem. Soc. 2006, 27, 1171-1174.

[11] A. Decortes, M. Martínez Belmonte, J. Bene $t$ Buchholz, A. W. Kleij, Chem. Commun. 2010, 46, 4580-4582. See also reference $4 \mathrm{~b}$.

[12] M. Alvaro, C. Baleizao, E. Carbonell, M. El Ghoul, H. García, B. Gigante, Tetrahedron 2005, 61, 12131-12139.

[13] Note that more tests were carried out (not reported in Table 1) with other VO(salen) compounds from Scheme 2; however, they all showed very low conversions. Note also that some results obtained while using $\left[\mathrm{V}(\mathrm{acac})_{3}\right]$ are reported in the Supporting Information.

[14] D. J. Darensbourg, A. Horn Jr, A. I. Moncada, Green Chem. 2010, 12, $1376-1379$.

[15] When the reaction was performed with $\left[\mathrm{VO}(\mathrm{acac})_{2}\right]$ as the catalyst, $\mathrm{NBu}_{4} \mathrm{I}$ as the co-catalyst and oxetane as the substrate in MEK at $45^{\circ} \mathrm{C}$ for $18 \mathrm{~h}$, a purple precipitate also formed, though in much smaller amounts when compared with the reaction that involved 1,2-epoxyhexane. Note that epoxides are more easily ring-opened by halides than 
oxetanes, thereby indicating that the substrate is actively involved in the formation of the precipitate.

[16] Recently, a very similar vanadate structure was published. In the current case, a slightly different pseudo-polymorph was analyzed. See: a) J. Forster, B. Rösner, M. M. Khusniyarov, C. Streb, Chem. Commun. 2011, 47 3114-3116. The tetraethylammonium analogue has also been reported: b) A. Bino, S. Cohen, C. Heitner-Wirguin, Inorg. Chem. 1982, 21, 429431.

[17] For some examples: a) S. S. Swapnil, A. H. Kategaonkar, M. N. Ware, C. H. Gill, B. B. Shingate, M. S. Shingare, ARKIVOC 2009, 2, 138-148; b) S. A Sadaphal, A. H. Kategaonkar, S. B. Sapkal, B. B. Shingate, C. H. Gill, M. S. Shingare, Bull. Catal. Soc. India 2009, 8, 131-139.

[18] a) M. P. Weberski, C. C. McLauchlan, C. G. Hamaker, Polyhedron 2006, 25, 119-123; b) C. J. Chang, J. A. Labinger, H. B. Gray, Inorg. Chem. 1997, 36, 5927-5930; c) J. A. Bonadies, C. J. Carrano, J. Am. Chem. Soc. 1986,
108, 4088; d) E. Tsuchida, K. Yamamoto, K. Oyazu, N. Iwasaki, F. C. Ansong, Inorg. Chem. 1994, 33, 1056-1063; e) V. Conte, F. Fabbianesi, B. Floris, P. Galloni, D. Sordi, I. W. C. E. Arends, M. Bonchio, D. Rehder, D. Bogdal, Pure Appl. Chem. 2009, 81, 1265-1277; f) N. F. Choudhary, N. G. Connely, P. B. Hitchcock, G. J. Leigh, J. Chem. Soc. Dalton Trans. 1999, 4437-4446; g) N. Choudhary, D. L. Hughes, U. Kleinkes, L. F. Larkworthy, G. J. Leigh, M. Maiwald, C. J. Marmion, J. R. Sanders, G. W. Smith, C. Sudbrake, Polyhedron 1997, 16, 1517-1528.

[19] G. M. Sheldrick, SHELXTL Crystallographic System Version 5.10, Bruker AXS, Inc. Madison (Wisconsin) 1998.

Received: November 4, 2011

Revised: December 20, 2012

Published online on April 13, 2012 